\title{
OPEN Author Correction: Extensive genomic diversity among Mycobacterium marinum strains revealed by whole genome sequencing
}

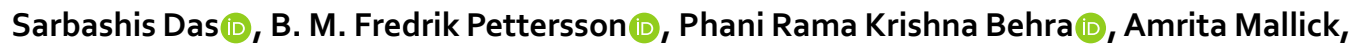
Martin Cheramie, Malavika Ramesh, Lisa Shirreff, Tanner DuCote, Santanu Dasgupta, Don G. Ennis \& Leif. A. Kirsebom

Correction to: Scientific Reports https://doi.org/10.1038/s41598-018-30152-y, published online 13 August 2018

The Article contains an error in Table 1 where the 'Host' column for the strain 'DE4576/Huestis' is incorrectly listed.

"Zebrafish (Danio rerio), outbreak of the ZIRC National zebrafish facility"

should read:

“Zebrafish (Danio rerio), outbreak of a laboratory facility, University of Oregon”

Additionally, in the 'Isolated from' column for the strain 'DE4576/Huestis', the city 'Eugene' is missing.

"Oregon, USA"

should read:

"Eugene, Oregon, USA"

(c) Open Access This article is licensed under a Creative Commons Attribution 4.0 International (c) License, which permits use, sharing, adaptation, distribution and reproduction in any medium or format, as long as you give appropriate credit to the original author(s) and the source, provide a link to the Creative Commons license, and indicate if changes were made. The images or other third party material in this article are included in the article's Creative Commons license, unless indicated otherwise in a credit line to the material. If material is not included in the article's Creative Commons license and your intended use is not permitted by statutory regulation or exceeds the permitted use, you will need to obtain permission directly from the copyright holder. To view a copy of this license, visit http://creativecommons.org/licenses/by/4.0/.

(C) The Author(s) 2020 